\title{
Evaluation of liquefaction potentials based on shear wave velocities in Pohang City, South Korea
}

\author{
Yumin $\mathrm{Ji}^{1}$, Byungmin $\mathrm{Kim}^{1 *}$ (iD and Kiseog Kim²
}

*Correspondence:
byungmin.kim@unist.ac.kr
${ }^{1}$ School of Urban
and Environmental
Engineering, Ulsan National
Institute of Science
and Technology (UNIST),
50 UNIST-gil, Eonyang-eup,
Ulju-gun, Ulsan 44919, South
Korea
Full list of author information
is available at the end of the
article

${ }^{*}$ Correspondence: byungmin.kim@unist.ac.kr Engineering, Ulsan National Institute of Science and Technology (UNIST), 50 UNIST-gil, Eonyang-eup, Korea is available at the end of the article

\begin{abstract}
This study evaluates the potentials of liquefaction caused by the 2017 moment magnitude 5.4 earthquake in Pohang City, South Korea. We obtain shear wave velocity profiles measured by suspension PS logging tests at the five sites near the epicenter. We also perform downhole tests at three of the five sites. Among the five sites, the surface manifestations (i.e., sand boils) were observed at the three sites, and not at the other two sites. The maximum accelerations on the ground surface at the five sites are estimated using the Next Generation Attenuation relationships for Western United State ground motion prediction equations. The shear wave velocity profiles from the two tests are slightly different, resulting in varying cyclic resistance ratios, factors of safety against liquefaction, and liquefaction potential indices. Nevertheless, we found that both test approaches can be used to evaluate liquefaction potentials. The liquefaction potential indices at the liquefied sites are approximately 1.5-13.9, whereas those at the non-liquefied sites are approximately 0-0.3.
\end{abstract}

Keywords: Liquefaction, Suspension PS logging test, Downhole test, Shear wave velocity, Liquefaction potential index

\section{Introduction}

An earthquake with a moment magnitude (M) of 5.4 struck Pohang City in South Korea on November 15, 2017. Small to moderate earthquakes frequently occur in the coastal areas of South Korea. However, the Pohang earthquake is distinct from the other earthquakes in South Korea because it caused significant damage and thus was recorded as the second strongest earthquake (e.g., $[17,18,20])$. The focal depth of the Pohang earthquake was less than $4 \mathrm{~km}$, which is considerably shallow, and it caused severe seismic loading on the ground. The Pohang earthquake induced sand boils near the epicenter. Because most liquefactions occurred in the rice paddies, there was no significant structural and geotechnical damage from liquefaction. However, note that liquefaction can occur in South Korea owing to small to moderate earthquakes.

Seed and Idriss [26] first proposed a simplified method to evaluate the triggering liquefaction at a certain depth with blow counts of the standard penetration test (SPT). Later, the liquefaction potential has been evaluated mainly using the blow counts of the 
SPT (e.g., [8, 12, 27, 29] and cone resistance of the cone penetration test (CPT) (e.g., [5, $21,23,25,30]$. The shear wave velocity $\left(V_{S}\right)$ measured from the downhole test, suspension PS logging test, and surface wave test have also been used in liquefaction assessment $[2,3,16,19]$.

Iwasaki et al. [14] suggested a liquefaction potential index (LPI) predicting the severity of liquefaction at a specific site. The LPI is calculated with factors of safety against liquefaction at various depths. It can be used as a preliminary guideline for evaluating soil liquefaction. When $0<\mathrm{LPI}<5$, the liquefaction potential is expected to low. However, when the LPI $>15$, the liquefaction potential is considered to be high [13].

In this study, we calculated factors of safety against liquefaction (FS ${ }^{\text {liq }}$ ) following the guide from Andrus et al. [3]. We also calculate the LPI values as indices of liquefaction potentials at the five select sites near the epicenter of the Pohang earthquake. Liquefaction-induced sand boils were observed at the three sites and not at the other two sites. More details about the five sites will be discussed in the subsequent section.

\section{Study area and sand boils}

The epicenter of the Pohang earthquake was in the northern part of Pohang City, where most of the land is used for agricultural and residential fields. We define the study area covering the field test sites and the epicenter, as shown in Fig. 1. The geology of Pohang City is comprised of Quaternary, Cretaceous, and Tertiary systems. The soil deposits include sedimentary, colluvial, and fill soils underlain by soft rocks or weathered soil and

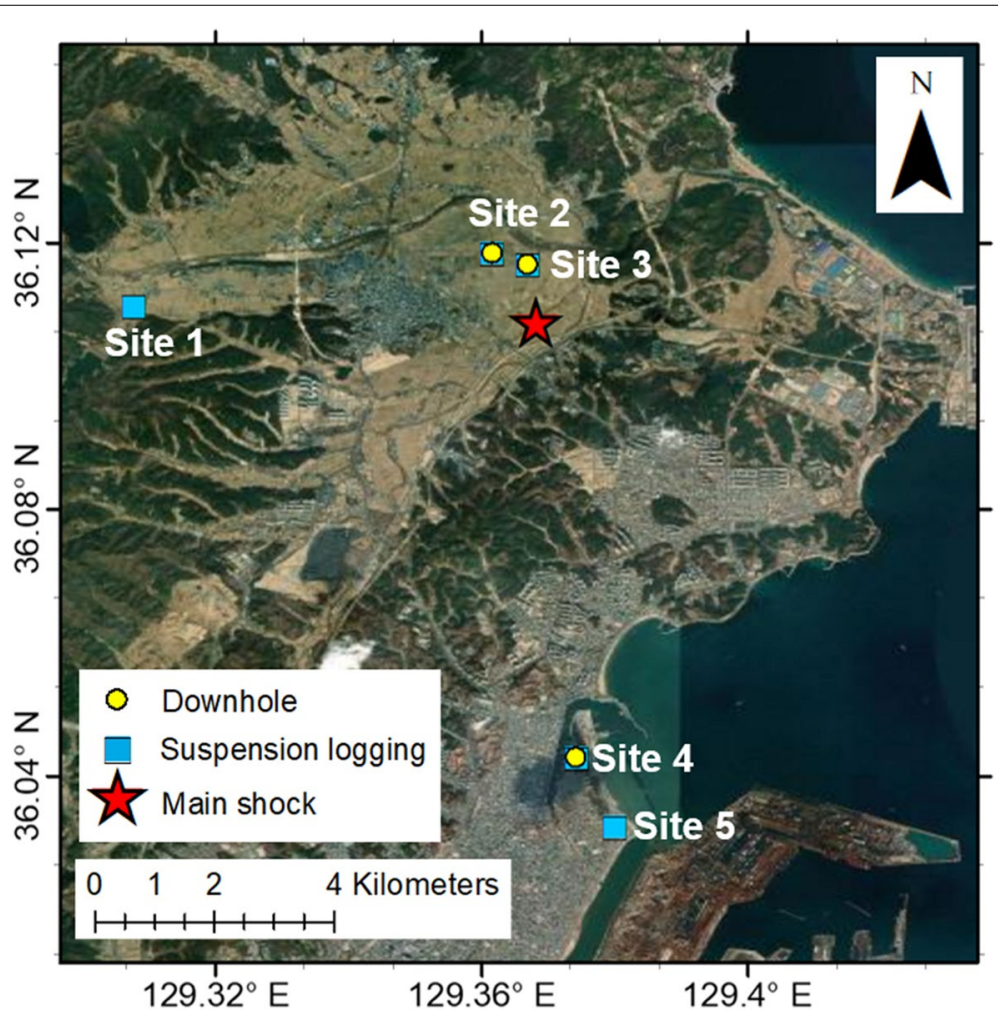

Fig. 1 Map of study area in Pohang City, where the locations of field tests and the epicenter of Pohang earthquake are shown 


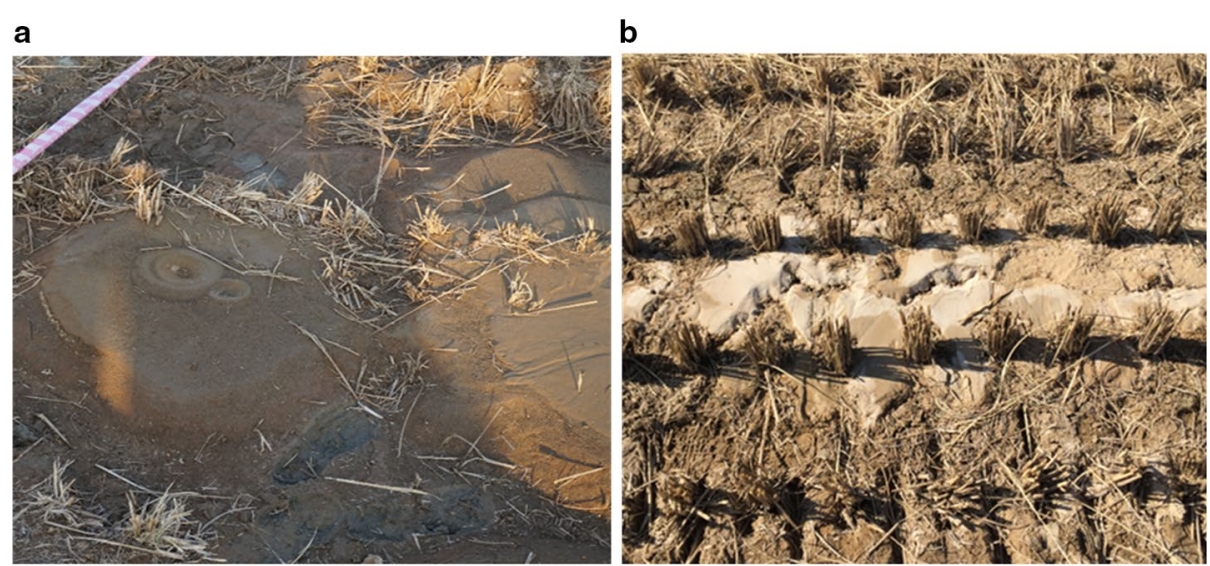

Fig. 2 Photos of sand boils that occurred in rice paddies near the epicenter during the Pohang earthquake

Table 1 Epicentral distances, $v_{s 30}$, and estimated $a_{\max }$ values for the five sites (see Fig. 1 for location)

\begin{tabular}{|c|c|c|c|c|c|c|c|c|}
\hline & $\begin{array}{l}\text { Epicenter } \\
\text { distance } \\
(\mathbf{k m})\end{array}$ & $\begin{array}{l}V_{S 30} \\
\text { from S-PS } \\
(\mathrm{m} / \mathrm{s})\end{array}$ & $\begin{array}{l}V_{\text {S30 }} \\
\text { from downhole } \\
(\mathrm{m} / \mathrm{s})\end{array}$ & $\begin{array}{l}a_{\max } \\
\text { for S-PS } \\
\text { (g) }\end{array}$ & $\begin{array}{l}a_{\max } \\
\text { for downhole } \\
\text { (g) }\end{array}$ & $\mathrm{LPI}^{\mathrm{S}}$ & $\mathrm{LPI}^{\mathrm{D}}$ & $\begin{array}{l}\text { Liquefaction } \\
\text { occurrence }\end{array}$ \\
\hline Site 1 & 5.5 & 522.5 & - & 0.25 & - & 0 & - & $x$ \\
\hline Site 2 & 1.4 & 272.3 & 251.6 & 0.39 & 0.39 & 13.9 & 7.6 & 0 \\
\hline Site 3 & 1.1 & 357.6 & 321.3 & 0.42 & 0.41 & $11.2\left(0^{\mathrm{a}}\right)$ & $9.8\left(0^{\mathrm{a}}\right)$ & $\mathrm{O}$ \\
\hline Site 4 & 7.3 & 188.1 & 161.7 & 0.23 & 0.22 & 1.5 & 2.9 & $\mathrm{O}$ \\
\hline Site 5 & 8.5 & 186.8 & - & 0.21 & - & 0.3 & - & $x$ \\
\hline
\end{tabular}

a The LPI values excluding clay layers

rocks with low stiffness [18]. The study area is on the Quaternary Alluvium, including Heunghae formation, Idong Formation, and Duho Formation [10].

After the Pohang earthquake, Gihm et al. [11] observed that 601 sand boils occurred near Pohang City, of which approximately $96 \%$ occurred in a $5 \mathrm{~km}$ radius of the epicenter. Gihm et al. [11] reported that the extruded sand boils consisted of $10 \%$ clay and silt, $30 \%$ sand with gravel, and $60 \%$ sand. Photographs of the observed sand boils are shown in Fig. 2.

The information of the five sites are shown in Table 1. Site 1-3 are located at the rice fields in the northern part of Pohang city. Especially, Site 2 and 3 are very close to the epicenter of the Pohang earthquake. Site 4-5 are located close to the coast in the southern part of the city. We considered that Site $2-4$ are liquefied sites based on observations of sand boils, and Site 1 and 5 are non-liquefied sites without sand boil observations.

\section{Shear wave velocity measurements}

We obtained five $V_{S}$ profiles measured by suspension PS logging test from the National Disaster Management Research Institute [24]. In this study, the three $V_{S}$ profiles were measured by downhole tests. Andrus et al. [3] summarized the primary features of suspension PS logging and the downhole test for liquefaction evaluation. Both tests require 

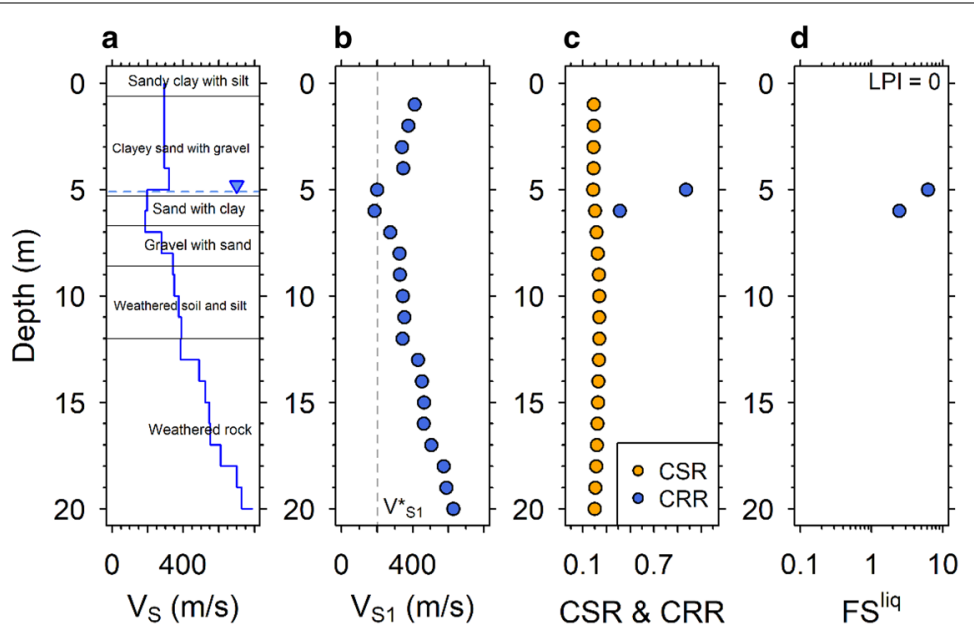

Fig. 3 Profiles of a raw $V_{S}$ measured from the downhole test; $\mathbf{b}$ corrected $V_{S}$ by an overburden stress $\left(V_{S 1}\right)$; c cyclic stress ratio and cyclic resistance ratio (CSR and CRR, respectively); and $\mathbf{d}$ factor of safety against liquefaction (FSliq) at Site 1, where sand boils were not observed (non-liquefied site). The LPI is shown at the top right of (d). The sand with clay at a depth of $6 \mathrm{~m}$ has a fines content of $16.2 \%$

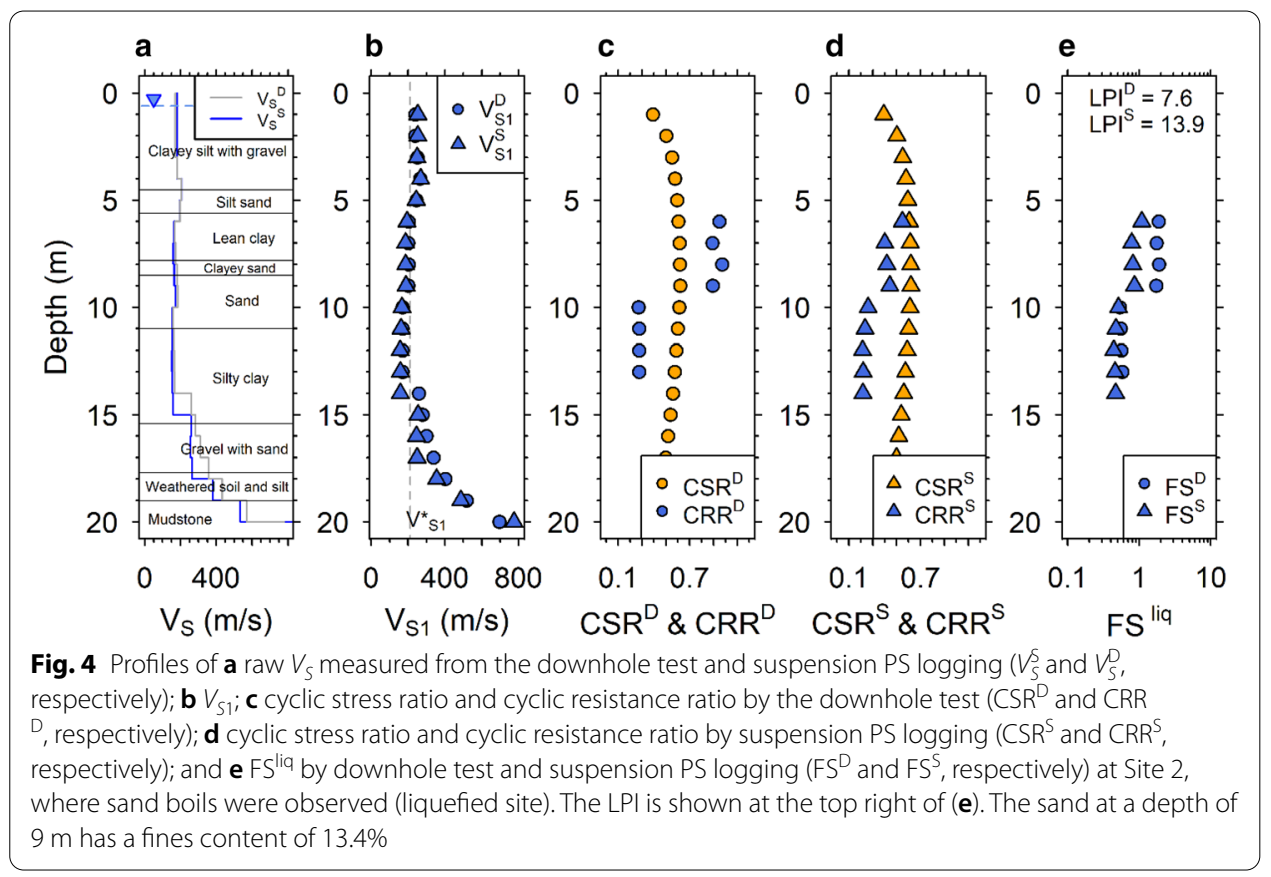

a borehole and are appropriate for detailed site-specific evaluation where thin soil layers exist.

Figure 3a presents the $V_{S}$ profiles obtained by the suspension PS logging test at Site 1 (liquefied). The $V_{S}$ gradually increases with depth and is greater than $200 \mathrm{~m} / \mathrm{s}$ at all depths. Figures 4a, 5 and $6 a$ present the comparisons of $V_{S}$ profiles measured by the suspension PS logging $\left(V_{S}^{S}\right)$ and downhole $\left(V_{S}^{D}\right)$ tests at Sites 2-4 (all liquefied sites), respectively. In Fig. 4a, the $V_{S}^{S}$ and $V_{S}^{D}$ profiles are in sufficient agreement throughout all depths. The $V_{S}^{S}$ and $V_{S}^{D}$ are approximately $200 \mathrm{~m} / \mathrm{s}$ up to a depth of $14 \mathrm{~m}$; the velocities increase as the depth increases. 


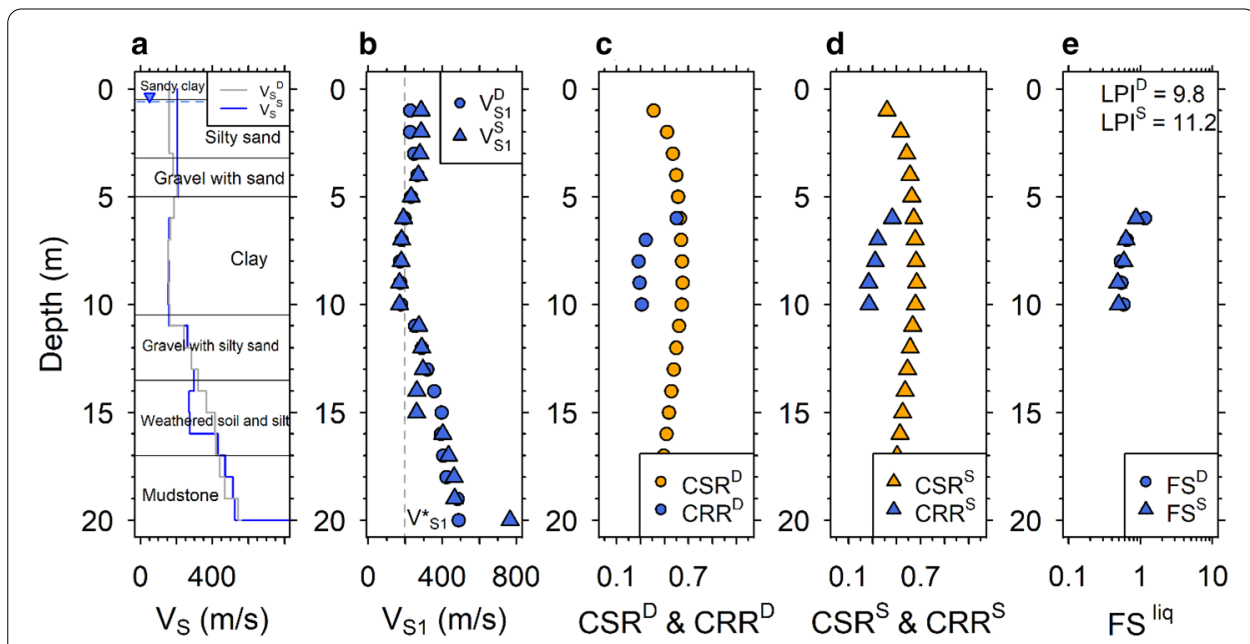

Fig. 5 Profiles of $\mathbf{a} V_{S}^{S}$ and $V_{S}^{D} ; \mathbf{b} V_{S 1} ; \mathbf{c} C S R^{D}$ and $C R R^{D} ; \mathbf{d} C S R^{S}$ and $C R R^{S}$; and $\mathbf{e} \mathrm{FS}^{\mathrm{D}}$ and $\mathrm{FS}^{S}$ at Site 3 , where sand boils were observed (liquefied site). The LPI is shown at the top right of (e). The silty sand at a depth of $3 \mathrm{~m}$ has a fines content of $12.8 \%$

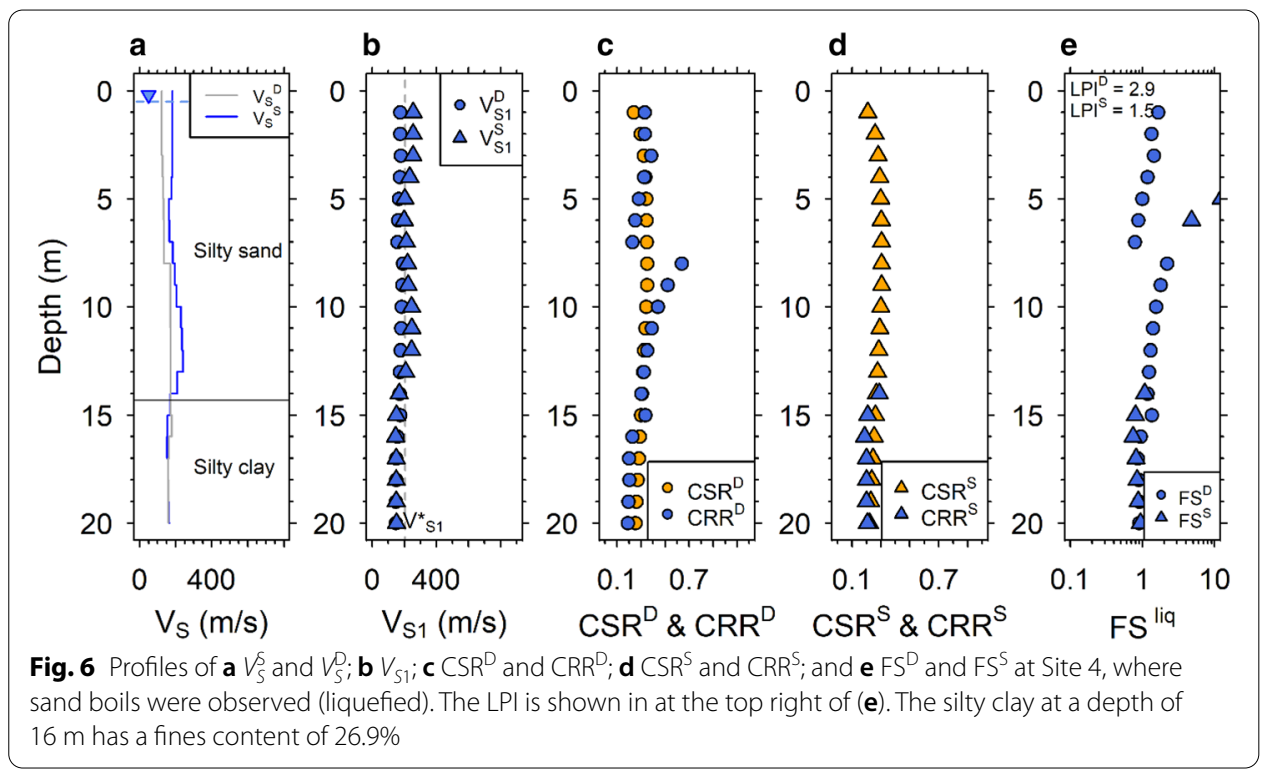

Figure 5a presents the liquefied site where $V_{S}^{S}$ and $V_{S}^{D}$ are similar at depths of 4-11 $\mathrm{m}$ and are lower than $200 \mathrm{~m} / \mathrm{s}$. Exceeding a depth of $4 \mathrm{~m}, V_{S}^{\delta}$ is approximately $204 \mathrm{~m} / \mathrm{s}$, which is slightly higher than $V_{S}^{D}(181 \mathrm{~m} / \mathrm{s})$. As shown in Fig. 6a, $V_{S}^{S}$ and $V_{S}^{D}$ are lower than $250 \mathrm{~m} / \mathrm{s}$ throughout all depths, and $V_{S}^{S}$ is slightly greater than $V_{S}^{D}$, up to a depth of $14 \mathrm{~m}$. Figure $7 \mathrm{a}$ presents the $V_{S}^{S}$ Site 5 (non-liquefied), which is lower than $200 \mathrm{~m} / \mathrm{s}$ at all depths.

\section{Liquefaction potential index}

We calculated the cyclic stress ratio (CSR) with the simplified procedure proposed by Seed and Idriss [26]. The detailed guide from Andrus et al. [3] was adopted to assess the cyclic resistance ratio (CRR) based on the $V_{S}$ profiles from the field tests. 

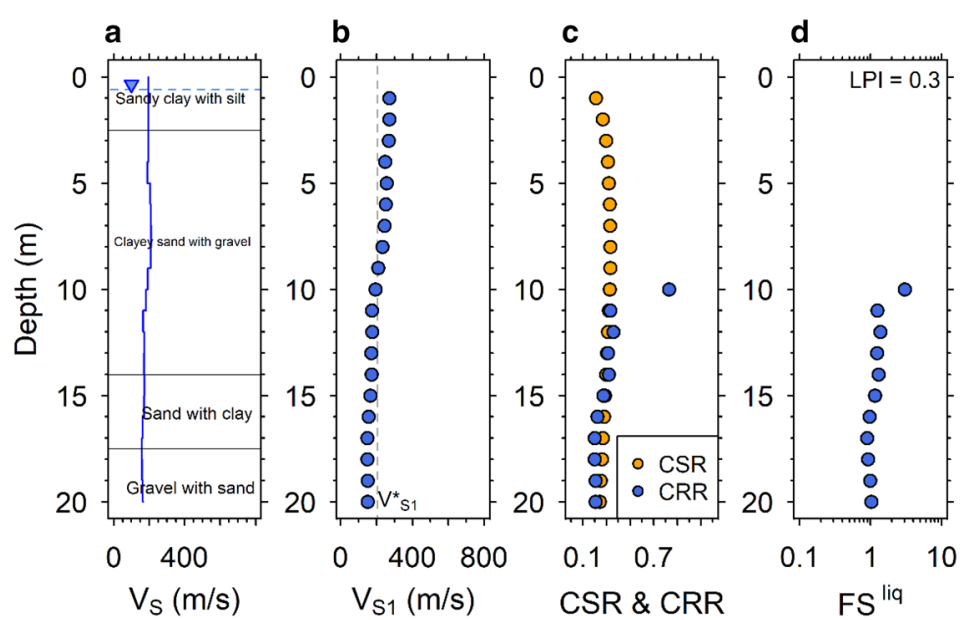

Fig. 7 Profiles of a raw $V_{S}$ measured by the downhole test; $\mathbf{b} V_{S 1} ; \mathbf{c} C S R$ and CRR; and $\mathbf{d}$ FS liq at Site 5 , where sand boils were not observed (non-liquefied site). The LPI is shown at the top right of (d). The clayey sand with gravel at a depth of $12 \mathrm{~m}$ has a fines content of $26.4 \%$

\section{Cyclic stress ratio}

Seed and Idriss [26] defined CSR as the seismic loading on the soil as follows:

$$
\mathrm{CSR}=0.65 \cdot \frac{\mathrm{amax}}{\mathrm{g}} \cdot \frac{\sigma_{\mathrm{v}}}{\sigma_{\mathrm{v}}^{\prime}} \cdot \mathrm{r}_{\mathrm{d}}
$$

where $a_{\max }$ is the peak horizontal ground acceleration on the surface, $g$ is the gravitational acceleration, $\sigma_{v}$ is the total overburden stress in the vertical direction, $\sigma_{v}^{\prime}$ is the effective overburden stress in the vertical direction, and $r_{d}$ is the stress reduction factor.

To estimate the $a_{\max }$ for the five sites, we used the four Next Generation Attenuation relationships for Western United State (NGA-West2) ground motion prediction equations (GMPEs) (i.e., $[1,4,7,9])$ with equal weights. This is because recorded ground motions were absent in the study area. Parameters such as $\mathbf{M}$, epicenter distance, and time-averaged $V_{S}$ are required for the $30 \mathrm{~m}$ soil deposits $\left(V_{S 30}\right)$ to estimate $a_{\max }$. Suspension PS logging and downhole tests were both considered individually to evaluate the $V_{S 30}$. The parameters and estimated $a_{\max }$ for the five sites are presented in Table 1. The NGA-West2 GMPEs use the closest distance to the rupture plane $\left(R_{\text {rup }}\right)$ and BooreJoyner distance $\left(R_{j b}\right)$. However, the rupture plane of the Pohang earthquake is not well defined yet, and is known to be shallow and small. Therefore, we used the epicentral distance for the NGA-West2 GMPEs. The calculated $a_{\max }$ values were validated by Kim et al. [20] who compared the peak ground accelerations estimated by the select GMPEs with those from the recordings at the four nearest stations.

Site-specific soil conditions, such as soil type, ground water table (from the boring log at each site), and soil density (from the density logging test by NDMI [24], were considered in the calculation of $\sigma_{v}$ and $\sigma_{v}^{\prime}$. Figure 3c presents the calculated CSR profile at Site 1 (non-liquefied). The site is located $5 \mathrm{~km}$ away from the epicenter, and $a_{\max }$ is $0.25 \mathrm{~g}$, resulting in CSRs less than 0.3 throughout all depths. Figure 4c and d present the CSRs for the downhole and suspension logging tests $\left(\mathrm{CSR}^{\mathrm{D}}\right.$ and $\mathrm{CSR}^{\mathrm{S}}$, respectively) at Site 2 (liquefied). No difference is observed in $\mathrm{CSR}^{\mathrm{D}}$ and $\mathrm{CSR}^{\mathrm{S}}$ because both $a_{\max }$ values are 
identical. The CSR increases to approximately 0.5 up to a depth of $9 \mathrm{~m}$, below which the CSR decreases with depth due to $r_{d}$. The $\operatorname{CSR}^{\mathrm{D}}$ and $\operatorname{CSR}^{\mathrm{S}}$ for Site 3 (liquefied), as shown in Fig. $5 c$, d, respectively, are similar to each other and increase up to approximately 0.6. Figure $6 \mathrm{c}$ and d present the $\mathrm{CSR}^{\mathrm{D}}$ and $\mathrm{CSR}^{\mathrm{S}}$ profiles for Site 4 (liquefied), and Fig. $7 \mathrm{c}$ presents the $\mathrm{CSR}^{\mathrm{D}}$ profile at Site 5 (non-liquefied).

\section{Cyclic resistance ratio}

$V_{S}$ is used to indicate the soil rigidity against liquefaction. Similar to other common penetration tests, the evaluation of liquefaction potential based on $V_{S}$ also requires the correction to a reference stress of $100 \mathrm{kPa}\left(V_{S 1}\right)$ [3]. In addition, $V_{S 1}$ should be limited to the maximum upper value $\left(V_{S 1}^{*}\right)$ as that of liquefaction evaluation based on the SPT test [3]. In this study, the depths at which $V_{S 1}$ is greater than $V_{S 1}^{*}$ were considered non-liquefiable and excluded in the LPI calculation. An example of the $V_{S 1}$ calculation is shown in Fig. 3b through Fig. $7 \mathrm{~b}$.

Andrus and Stokoe II [2] suggested the CRR as follows:

$$
\mathrm{CRR}=\operatorname{MSF} \cdot\left\{0.022\left(\frac{\mathrm{K}_{\mathrm{a} 1} \mathrm{~V}_{\mathrm{S} 1}}{100}\right)^{2}+2.8\left(\frac{1}{\mathrm{~V}_{\mathrm{S} 1}^{*}-\left(\mathrm{K}_{\mathrm{a} 1} \mathrm{~V}_{\mathrm{S} 1}\right)}-\frac{1}{\mathrm{~V}_{\mathrm{S} 1}^{*}}\right) \mathrm{K}_{\mathrm{a}} 2\right\}
$$

where MSF is the magnitude scaling factor to consider the effect of $\mathbf{M}$ [29]. Further, $K_{a 1}$ and $K_{a 2}$ are the age correction factors for uncemented Holocene soils to older soils [2]. In this study, $K_{a 1}$ and $K_{a 2}$ are regarded as unity because the sediments in Pohang are Quaternary unconsolidated soils.

Example calculations of CRRs are presented in Fig. 3 through Fig. 7. Note that CRRs increase considerably as the $V_{S 1}$ values approach $V_{S 1}^{*}$ values in Eq. (2). Therefore, minor variations in $V_{S 1}$ can consequently cause significantly distinct CRRs, as shown in Fig. 4c, d.

\section{Liquefaction potential index}

The factor of safety against liquefaction $\left(\mathrm{FS}^{\mathrm{liq}}\right)$ is defined as the ratio of CRR to CSR. When CRR is greater than CSR, the liquefaction potential is considered to be low, and vice versa. FS ${ }^{\text {liq }}$ varies with depth. Iwasaki et al. [14] proposed a liquefaction potential index that represents the susceptibility of ground to liquefaction at a site as follows:

$$
\text { LPI }=\int_{0}^{20 m} F(z) w(z) d z
$$

where $z$ is the depth, $w$ is the weighting function, which equals $10-0.5 z$ if $z$ is less than $20 \mathrm{~m} . F$ is a function of $\mathrm{FS}^{\mathrm{liq}}$ at a given depth (i.e., $F=1-\mathrm{FS}^{\mathrm{liq}}$ if $\mathrm{FS}^{\mathrm{liq}}$ is less than 1; otherwise it is zero).

Figure $3 \mathrm{~d}$ presents the calculated FS ${ }^{\text {liq }}$ at Site 1 . The FS ${ }^{\text {liq }}$ value is greater than 1.0 at depths of 5-6 m. Below $6 \mathrm{~m}, V_{S 1}$ is greater than the liming value; thus, the soil layers are not liquefiable. As a result, the LPI was calculated to be zero, which is consistent with the field observation: no sand boil was observed. Figure 4e presents FS ${ }^{\text {liq }}$ at Site 2 . The slight variation in $V_{S}$ resulted in a $\mathrm{FS}^{\text {liq }}$ difference (i.e., $\mathrm{FS}^{\mathrm{D}} \mathrm{vs} \mathrm{FS}^{\mathrm{S}}$ ) of approximately 1.0 
at depths of 6-9 m. The $\mathrm{V}_{\mathrm{S} 1}^{\mathrm{S}}$ varies from 185 to $194 \mathrm{~m} / \mathrm{s}$ at these depths while $\mathrm{V}_{\mathrm{S} 1}^{\mathrm{D}}$ varies from 202 to $203 \mathrm{~m} / \mathrm{s}$. The difference in $V_{S 1}$ resulted in the difference in CRR. Although the $V_{S 1}^{\mathrm{D}}$ values are analogous to $V_{S 1}^{S}$, they are very close to the $V_{S 1}^{*}$, causing greater values of $\mathrm{CRR}^{\mathrm{D}}$ than $C R R^{\mathrm{S}}$. Below a depth of $10 \mathrm{~m}, \mathrm{FS}^{\text {liq }}$ is lower than 1.0 for both downhole and suspension PS logging tests. The LPI ${ }^{\mathrm{D}}$ was calculated to be 7.6, and the $\mathrm{LPI}^{\mathrm{S}}$ was 13.9. Numerous studies have reported that sand boils could occur when an LPI is greater than $5[15,22,28]$. Therefore, it can be concluded that both LPIs are in sufficient agreement with the sand boil observations at this site.

Figure 5e presents the FS ${ }^{\text {liq }}$ at Site 3 (liquefied). The $\mathrm{FS}^{\mathrm{D}}$ and $\mathrm{FS}^{\mathrm{S}}$ are significantly similar throughout all depths, and the $\mathrm{LPI}^{\mathrm{D}}$ and $\mathrm{LPI}^{\mathrm{S}}$ were calculated to be 9.8 and 11.2, respectively. It is known that clays are not susceptible to liquefaction. However, recently, lean clays are considered to be moderately susceptible to liquefaction (e.g., [6]). Without knowing exact composition of the clay layer at this site, we included the clay layer in the LPI calculation. When this clay layer was excluded, the LPIs for both downhole and suspension logging tests are zeros, which is not consistent with the sand boil observation. A further in-depth study is required for susceptibility of the clay layer at this site.

Figure 6e presents FS ${ }^{\text {liq }}$ at Site 4 (liquefied), and the $\mathrm{LPI}^{\mathrm{D}}$ and $\mathrm{LPI}^{\mathrm{S}}$ were calculated to be 2.9 and 1.5 , respectively. It is worth noting that slight differences in measured $V_{S}$ from different methods can result in considerable differences in $\mathrm{FS}^{\mathrm{liq}}$ as shown in Fig. 6a, d. The $V_{S 1}^{S}$ values at depths of 1-4 $\mathrm{m}$ and 7-13 $\mathrm{m}$ were greater than $\mathrm{V}_{\mathrm{S} 1}^{*}$ and were excluded in calculation. At depths of 5-6 m, the differences between $V_{S 1}^{D}$ and $V_{S 1}^{S}$ are approximately $35.8-38 \mathrm{~m} / \mathrm{s}$, which resulted in the differences between $\mathrm{FS}^{\mathrm{D}}$ and $\mathrm{FS}^{\mathrm{S}}$ of approximately 3.9-11.4. Figure 7e presents that FS ${ }^{\text {liq }}$ at Site 5 (non-liquefied) is near 1.0 at depths greater than $11 \mathrm{~m}$. The LPI was calculated to be 0.3 for this site. The calculated LPIs at all sites are summarized in Table 1. The LPIs at the liquefied sites are higher than 1.0, and those at the non-liquefied sites are lower than 1.0.

\section{Conclusions}

This study presents the evaluation of liquefaction potentials based on the $V_{S}$ profiles measured by both downhole and suspension PS logging tests at five selected sites. The $V_{S}$ profiles from both tests were generally in good agreement. However, there are some cases with slight differences, resulting in varying CRR. In particular, when the values of $V_{S 1}$ approached that of $V_{S 1}^{*}$, the CRR calculation became highly sensitive. Owing to the lack of ground motion records within the study area, we estimated the CSR by using the NGA-West2 GMPEs.

The LPIs from the suspension PS logging test were calculated to be approximately 1.513. 9 for the three liquefaction sites, and those from the downhole tests were approximately 2.9-9.8. The LPIs were calculated to be 0 and 0.3 at the two non-liquefied sites. Therefore, both downhole and suspension PS logging tests can be used to evaluate liquefaction potentials.

\section{Acknowledgements}

This study was supported by grants (20SCIP-C151438-02) from the Construction Technologies Program funded by the Ministry of Land, Infrastructure and Transport of the Korean government and from the project entitled "Development of liquefaction damage prediction visualization system and liquefaction reinforcement method with high efficiency and low cost" which is funded by the Korea Institute of Civil Engineering and Building Technology (KICT). We would like to express our gratitude to the National Disaster Management Research Institute for providing valuable field test data. We also thank the two anonymous reviewers for their insightful feedback. 


\section{Authors' contributions}

YJ carried out the liquefaction evaluations and drafted the manuscript. BK was involved in drafting and revising the manuscript. KK was in charge of conducting the field tests. All authors read and approved the final manuscript.

\section{Competing interests}

The authors declare that they have no competing interests.

\section{Author details}

${ }^{1}$ School of Urban and Environmental Engineering, Ulsan National Institute of Science and Technology (UNIST), 50 UNIST-gil, Eonyang-eup, Ulju-gun, Ulsan 44919, South Korea. ${ }^{2}$ Heesong Geotek Co., Ltd., Jungwon-gu, Seongnam-si, Gyeonggi-do, Seoul 13209, South Korea.

Received: 15 September 2020 Accepted: 18 November 2020

Published online: 26 January 2021

\section{References}

1. Abrahamson NA, Silva WJ, Kamai R (2014) Summary of the ASK14 ground motion relation for active crustal regions. Earthquake Spectra 30:1025-1055

2. Andrus RD, Stokoe KH II (2000) Liquefaction resistance of soils from shear-wave velocity. J Geotech Geoenviron Eng 126:1015-1025

3. Andrus RD, Stokoe KH II, Hsein Juang C (2004) Guide for shear-wave-based liquefaction potential evaluation. Earthquake Spectra 20:285-308

4. Boore DM, Stewart JP, Seyhan E, Atkinson GM (2014) NGA-West2 equations for predicting PGA, PGV, and 5\% damped PSA for shallow crustal earthquakes. Earthquake Spectra 30:1057-1085

5. Boulanger R, Idriss I (2014) CPT and SPT based liquefaction triggering procedures Report No UCD/CGM-14 1

6. Bray JD, Sancio RB (2006) Assessment of the liquefaction susceptibility of fine-grained soils. J Geotech Geoenviron Eng 132:1165-1177

7. Campbell KW, Bozorgnia Y (2014) NGA-West2 ground motion model for the average horizontal components of PGA, PGV, and 5\% damped linear acceleration response spectra. Earthquake Spectra 30:1087-1115

8. Cetin KO, Seed RB, Der Kiureghian A, Tokimatsu K, Harder LF Jr, Kayen RE, Moss RE (2004) Standard penetration testbased probabilistic and deterministic assessment of seismic soil liquefaction potential. J Geotech Geoenviron Eng 130:1314-1340

9. Chiou BS-J, Youngs RR (2014) Update of the Chiou and Youngs NGA model for the average horizontal component of peak ground motion and response spectra. Earthquake Spectra 30:1117-1153

10. Geological Survey of Korea (1964) Explanatory text of the geological map of pohang sheet (SHEET 7022-II) scale 1:50,000

11. Gihm YS et al. (2018) Paleoseismological implications of liquefaction-induced structures caused by the 2017 Pohang earthquake. Geosci J:871-880

12. Idriss I, Boulanger RW (2010) SPT-based liquefaction triggering procedures. Rep UCD/CGM-10 2:4-13

13. Iwasaki T, Arakawa T, Tokida K-I (1984) Simplified procedures for assessing soil liquefaction during earthquakes. Int J Soil Dyn Earthq Eng 3:49-58

14. Iwasaki T, Tatsuoka F, Tokida K, Yasuda S (1978) A practical method for assessing soil liquefaction potential based on case studies at various sites in Japan. In: Proceedings of second international conference microzonation safer construction research application; 1978. pp 885-896

15. Iwasaki T, Tokida K, Tatsuoka F, Watanabe S, Yasuda S, Sato H (1982) Microzonation for soil liquefaction potential using simplified methods. In: Proceedings of the 3rd international conference on microzonation, Seattle. pp 1310-1330

16. Juang $\mathrm{CH}$, Yang SH, Yuan H (2005) Model uncertainty of shear wave velocity-based method for liquefaction potential evaluation. J Geotech Geoenviron Eng 131:1274-1282

17. Kang SH, Kim BM, Bae SJ, Lee HJ, Kim MR (2019) Earthquake-induced ground deformations in the low-seismicity region: a case of the 2017 M5. 4 Pohang, South Korea, earthquake. Earthquake Spectra 35:1235-1260

18. Kang SH, Kim BM, Cho HI, Lee JY, Kim KS, Bae SJ, Sun CG (2019b) Ground Motion Amplifications in Small-Size Hills: Case Study of Gokgang-ri, South Korea, during the 2017 ML5.4 Pohang Earthquake Sequence Bulletin of the Seismological Society of America

19. Kayen $\mathrm{R}$ et al. (2013) Shear-wave velocity-based probabilistic and deterministic assessment of seismic soil liquefaction potential. J Geotech Geoenviron Eng 139:407-419

20. Kim H-S, Kim M, Laurie GB, Kim B (2020) Local and regional evaluation of liquefaction potential index and liquefaction severity number for liquefaction-induced sand boils in Pohang, South Korea. Soil Dyn Earthq Eng 7:24

21. Maurer B, Green R, Cubrinovski M, Bradley B (2015) Assessment of CPT-based methods for liquefaction evaluation in a liquefaction potential index framework. Géotechnique 65:328-336

22. Maurer BW, Green RA, Cubrinovski M, Bradley BA (2014) Evaluation of the liquefaction potential index for assessing liquefaction hazard in Christchurch, New Zealand. J Geotech Geoenviron Eng 140:04014032. https://doi. org/10.1061/(ASCE)GT.1943-5606.0001117

23. Moss R, Seed RB, Kayen RE, Stewart JP, Der Kiureghian A, Cetin KO (2006) CPT-based probabilistic and deterministic assessment of in situ seismic soil liquefaction potential. J Geotech Geoenviron Eng 132:1032-1051

24. NDMI (2018) Liquefacion hazard evaluation in Pohang, South Korea, National Disaster Management Research Institute. p. 58

25. Seed HB, Idriss I (1981) Evaluation of liquefaction potential sand deposits based on observation of performance in previous earthquakes. In: ASCE national convention (MO). pp 481-544 
26. Seed HB, Idriss IM (1971) Simplified procedure for evaluating soil liquefaction potential. J Soil Mech Found Div 97:1249-1273

27. Seed HB, Tokimatsu K, Harder LF, Chung R (1985) Influence of SPT procedures in soil liquefaction resistance evaluations. J Geotech Eng 111:1425-1445

28. Toprak S, Holzer TL (2003) Liquefaction potential index: field assessment. J Geotech Geoenviron Eng 129:315-322. https://doi.org/10.1061/(ASCE)1090-0241(2003)129:4(315)

29. Youd TL, Idriss IM, Andrus RD, Arango I, Castro G, Christian JT (2001) Liquefaction resistance of soils: summary report from the 1996 NCEER and engineering NCEER/NSF workshops on evaluation of liquefaction resistance of soils. J Geotech Geoenviron Eng 127:297-313

30. Zhou S (1980) Evaluation of the liquefaction of sand by static cone penetration test. In: Proceedings, 7th world conference on earthquake engineering

\section{Publisher's Note}

Springer Nature remains neutral with regard to jurisdictional claims in published maps and institutional affiliations.

Submit your manuscript to a SpringerOpen ${ }^{\circ}$ journal and benefit from:

- Convenient online submission

- Rigorous peer review

- Open access: articles freely available online

- High visibility within the field

Retaining the copyright to your article

Submit your next manuscript at $\gg$ springeropen.com 